\title{
Review \\ Low-Glycemic Index Diets as an Intervention in Metabolic Diseases: A Systematic Review and Meta-Analysis
}

\author{
Chunxiao $\mathrm{Ni}^{1,2}{ }^{1}$, Qingqing Jia ${ }^{1,3}$, Gangqiang Ding ${ }^{1,2}$, Xifeng $\mathrm{Wu}^{1,3}$ and Min Yang ${ }^{1,2, *}$ \\ 1 The School of Public Health, Zhejiang University, Hangzhou 310027, China; nichunxiao@zju.edu.cn (C.N.); \\ 13260930655@163.com (Q.J.); dinggq@chinacdc.cn (G.D.); xifengw@zju.edu.cn (X.W.) \\ 2 National Institute for Nutrition and Health, Chinese Center for Disease Control and Prevention, \\ Beijing 100050, China \\ 3 The Center of Clinical Big Data and Analytics, Second Affiliated Hospital, Zhejiang University School of \\ Medicine, Hangzhou 310030, China \\ * Correspondence: ymin36@zju.edu.cn; Tel./Fax: +86-571-8820-8099
}

check for updates

Citation: Ni, C.; Jia, Q.; Ding, G.; Wu, X.; Yang, M. Low-Glycemic Index Diets as an Intervention in Metabolic Diseases: A Systematic Review and Meta-Analysis. Nutrients 2022, 14, 307. https://doi.org/10.3390/ nu14020307

Academic Editor: Mario Barbagallo

Received: 14 December 2021

Accepted: 9 January 2022

Published: 12 January 2022

Publisher's Note: MDPI stays neutral with regard to jurisdictional claims in published maps and institutional affiliations.

Copyright: (c) 2022 by the authors. Licensee MDPI, Basel, Switzerland. This article is an open access article distributed under the terms and conditions of the Creative Commons Attribution (CC BY) license (https:// creativecommons.org/licenses/by/ $4.0 /)$.

\begin{abstract}
We aimed to investigate the effects of a low-glycemic index (GI) diet on the body mass and blood glucose of patients with four common metabolic diseases by conducting a systematic review and meta-analysis of studies comparing a low-GI diet (LGID) and other types of diet. Search terms relating to population, intervention, comparator, outcomes, and study design were used to search three databases: PubMed, Embase, and the Cochrane Library. We identified 24 studies involving 2002 participants. Random-effects models were used for 16 studies in the meta-analysis and stratified analyses were performed according to the duration of the intervention. The systematic review showed that LGIDs slightly reduced body mass and body mass index (BMI) $(p<0.05)$. BMI improved more substantially after interventions of $>24$ weeks and there was no inter-study heterogeneity $\left(\mathrm{I}^{2}=0 \%\right.$, $p=0.48$; mean difference $(\mathrm{MD})=-2.02,95 \%$ confidence interval $(\mathrm{CI}):-3.05,-0.98)$. Overall, an LGID had superior effects to a control diet on fasting blood glucose (FBG) and glycosylated hemoglobin. When the intervention exceeded 30 days, an LGID reduced FBG more substantially $(\mathrm{MD}=-0.34$, 95\% CI: $-0.55,-0.12$ ). Thus, for patients with metabolic diseases, an LGID is more effective at controlling body mass and blood glucose than a high-GI or other diet.
\end{abstract}

Keywords: glycemic index; metabolic disease; body mass; BMI; blood glucose; glycosylated hemoglobin; randomized controlled trial; meta-analysis; systematic review

\section{Introduction}

The prevention and treatment of metabolic diseases, such as diabetes mellitus, cardiovascular disease, obesity, and the metabolic syndrome, are a global public health issue. Between 1990 and 2019, the number of patients with cardiovascular disease increased from 271 million to 523 million and the number of associated deaths increased from 12.1 million to 18.6 million [1]. The age-standardized disability-adjusted life year (DALYR) for diabetes increased by $24.4 \%$ between 1990 and 2019 [2]. By the year 2030, the global cost of managing diabetes is expected to reach USD 2.1 trillion [3]. According to the International Diabetes Federation (IDF) Diabetes Atlas, the global prevalence of diabetes is expected to increase to $10.4 \%$ by 2040 [4]. Without adjusting for secular trends, the number of obese adults is expected to reach 573 million by 2030, and if the long-term trends continue unabated, the number of individuals with obesity is projected to total 1.12 billion [5]. The global prevalence of metabolic syndrome is $\sim 25 \%$, meaning that $>2$ billion people worldwide are now affected [4]. These common metabolic diseases involve disorders in multiple metabolic pathways, including insulin signaling, insulin secretion, glucose utilization, thermogenesis, mitochondrial function, and autophagy [6] and are all related to obesity [7].

The glycemic index (GI) was first developed by Jenkins et al. in the early 1980s [8] and is an index of the effect of the consumption of carbohydrate-containing foods on 
postprandial glucose concentrations. GI is defined as the ratio of the area under the glucose curve (AUC) $2 \mathrm{~h}$ after consuming $50 \mathrm{~g}$ of carbohydrates in test food vs. that for standard food. In general, glucose or white bread is used as the reference food. The formula used is:

$$
\mathrm{GI}=\left(\text { AUC test } \frac{\text { food }}{\mathrm{AUC}} \text { reference food }\right) \times 100
$$

According to their GI, foods are divided into three categories: high-GI foods (GI $\geq 70)$, medium-GI foods $(55 \leq \mathrm{GI}<70)$, and low-GI foods $(\mathrm{GI}<55)$ [9-11].

The total carbohydrate intake in a mixed meal also directly affects the glycemic response, which has given rise to the concept of glycemic load (GL). GL can be calculated using the following formula:

$$
\mathrm{GL}=\mathrm{GI} \times \text { available carbohydrate in the food item }(\mathrm{g}) / 100 \text {. }
$$

GL is also categorized as low $(<10)$, intermediate (11-19), or high $(>20)$ [9].

When a mixed meal contains carbohydrates from several different sources, the effect of the low-GI component is diluted proportionately by the others. Therefore, the GI of a mixed diet can be calculated [12]. At present, there are two methods used to obtain the GI of a diet: one is to measure dietary GI directly and the other is to calculate it using the GI of the components. For the latter, the proportion of carbohydrate in each component is multiplied by the GI of each to obtain the contributions of each component, which are added together to obtain the diet's overall GI. Previous studies have shown that dietary GI values obtained using these two methods have high validity and that both can be used to accurately estimate the blood glucose response to a mixed diet [13].

Previous studies of the effects of low-GI diets (LGIDs) on metabolic diseases have generated inconsistent results. The study by Abete et al. showed that the effect of an LGID on weight loss was superior to that of a control diet [14], whereas the study by Mulyar et al. showed no difference [15]. The findings of studies by $\mathrm{Hu}$ et al. and Heilbronn et al. regarding the effects of LGIDs on blood glucose control also yielded opposing findings [16,17]. Single studies are often limited by their small sample size, differences in the characteristics of the participants, and sampling errors. In addition, the systematic reviews of the use of LGIDs published to date have focused on a single disease or only included observational studies. For example, those by Ojo et al. and Thomas et al. focused on diabetes alone [18-23] and those by Askari et al., Livesey et al., and Mirrahimi et al. only included observational studies $[18,22,23]$.

In the present study, we aimed to compare the effects of an LGID and other diets (American Diabetes Association diet, Mediterranean diet, low-glycemic index diet, modified Mediterranean diet, high-glycemic index diet, low-fat diet, low-glycemic index Mediterranean die, low-carbohydrate diet, high-cereal fiber diet, routine diet, low-glycemic load diet, high-glycemic load diet) on weight loss and glycemic control in patients with one of four common metabolic diseases (obesity, metabolic syndrome, diabetes mellitus, and cardiovascular disease) by performing a systematic review and meta-analysis of randomized controlled trials (RCTs).

\section{Materials and Methods}

\subsection{PRISMA Guidelines}

We report the present findings in accordance with the PRISMA statement for reporting systematic reviews and meta-analyses of studies that evaluate healthcare interventions [24].

\subsection{Data Sources and Search Strategy}

A comprehensive search strategy was designed for PubMed and modified for use in other databases. The search strategy was: 
(('glycemic index' OR 'glycemic indices' OR 'glycemic index number”' OR 'glycaemic index 'OR 'glycaemic indices' OR 'glycaemic index number*') OR ('glycemic load' OR 'glycaemic load') OR 'low-GI' OR ‘high-GI')

AND

(child OR children OR adolescent OR adolescence OR teenagers OR teenager OR youth OR adult OR elderly)

AND

('metabolic disease' OR diabetes OR pre-diabetes OR 'diabetes mellitus' OR 'cardiovascular disease' OR 'cardiovascular diseases' OR obesity OR 'metabolic syndrome' OR 'metabolism syndrome' OR 'metabolic syndromes')

AND

('randomized controlled trial' OR RCT)

AND

(diet OR dietary)

We searched the PubMed, Cochrane Library, and Embase databases. We did not restrict our search results by time or language. The final search was performed on 30 January 2021.

\subsection{Eligibility Criteria}

Studies were included if they met the following inclusion criteria: (1) the studies were RCTs conducted in children, adolescents or adults; (2) the participants had at least one of the following diseases: obesity, diabetes, metabolic syndrome, or cardiovascular disease; (3) the intervention was a diet that lowered or aimed to lower dietary GI and the control group consumed a high-GI, low-fat, low-carbohydrate, conventional weight-loss, or specialty diet; and (4) the study included data regarding body composition (e.g., body mass, BMI, or body fat content) or indices of blood glucose control (e.g., fasting blood glucose (FBG) or fasting insulin concentrations).

\subsection{Study Selection}

Abstracts and full-text articles were selected independently by two authors. Before further reading of each publication, neither researcher knew the results of the screening by the other. Disagreements were resolved by discussion, if necessary, with a third author.

\subsection{Study Quality}

Study quality was determined using the Cochrane Collaboration's tool for assessing the risk of bias in randomized trials [25]. This tool evaluates the risk of bias in randomized trials in six domains: selection bias, performance bias, detection bias, attrition bias, reporting bias, and other bias. The study quality was assessed individually by two authors, and disagreements were settled by discussion, if necessary, with a third author.

\subsection{Data Extraction}

Data extraction was performed independently by two authors and the output was checked jointly. The data extracted included the basic characteristics of the study, the RCTrelated characteristics, outcomes of interest, and study quality. We extracted the following data from each eligible article: the first author's name, year of publication, country where the trial was performed, disease type, sample size, sex ratio, BMI, BMI category, mean age, FBG, glycosylated hemoglobin ( $\mathrm{HbA1c} \%$ ), duration of the intervention, study length, randomization method, presence of blinding, energy restriction, intervention type, nature of the control group, GI, and percentage of carbohydrate consumed for the invention and control groups.

\subsection{Statistical Synthesis and Analysis}

Data from the included studies were subjected to meta-analysis using $\mathrm{R}$ version 4.1.0 (https://cloud.r-project.org/, accessed on 18 May 2021). This analysis was conducted 
to summarize the effects of an LGID on body mass, BMI, fasting glucose, and $\mathrm{HbA} 1 \mathrm{c} \%$ in individuals with diabetes, cardiovascular disease, obesity, or the metabolic syndrome. Heterogeneity testing was performed to evaluate the variability in the effects of the intervention [26]. If $p<0.05$, or $\mathrm{I}^{2}>40 \%$, it was considered that there was significant heterogeneity in the data, and a random-effects model was selected. Otherwise, it was considered that the data were homogeneous. The mean differences (MD) in parameters were used in fixed-effect models, alongside 95\% confidence intervals (CIs), and an $\alpha$ of 0.05 .

\section{Results}

\subsection{Results of the Literature Searches}

A flow chart describing the selection process and the detailed methods of study identification is presented in Figure 1. The primary search of the three databases yielded 1334 articles. Of these, 361 were duplicates, leaving 973 articles. The titles and abstracts of each were then scrutinized and 208 appropriate articles were selected. The full text inclusion criteria were applied to these, which yielded 24 articles for inclusion in the present analysis.

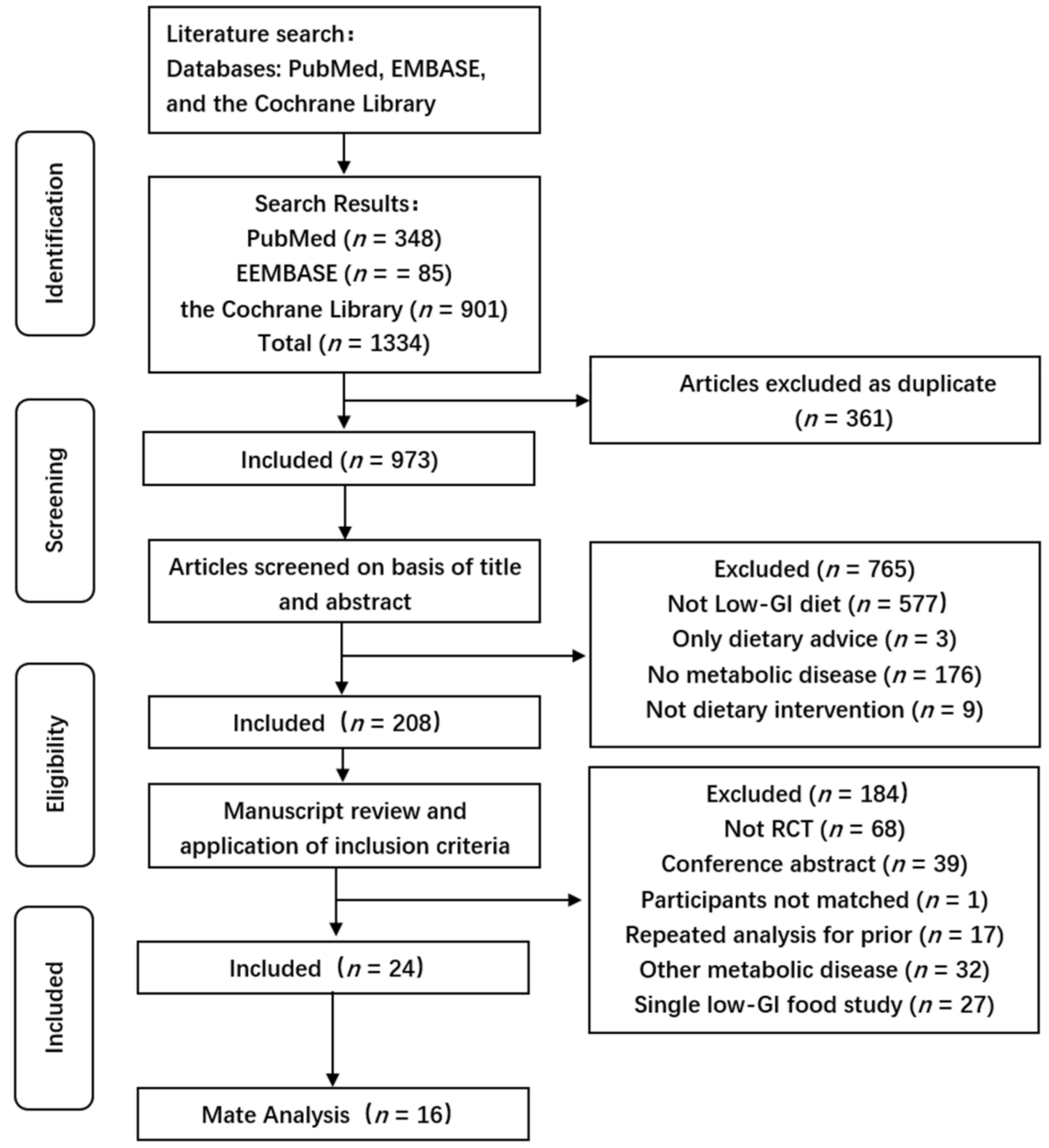

Figure 1. PRISMA flow diagram. Of an initial 1334 independent records, 361 were duplicates. A further 765 and 184 were excluded after scrutinization at the title/abstract and full-text levels, respectively, leaving 24 articles. Data from all 16 articles were included in the meta-analyses.

\subsection{Characteristics of the Included Studies}

The characteristics of the included studies are summarized in Table 1. The year of publication ranged from 2002 to 2020 . Most of the studies were conducted in the United States and two in China. There were 12 studies of patients with type 2 diabetes, one of 
gestational diabetes, two of metabolic syndrome, and nine of obesity. The sample sizes of the studies ranged from 19 to 210 , and except for those that included multiple control groups, the sample sizes of the intervention and control groups were relatively balanced. Two of the studies were of women alone, while the sex distribution of the others was more even. The BMIs of the participants ranged from 24.3 to $36.3 \mathrm{~kg} / \mathrm{m}^{2}$. The average age ranged from 12 to 66.2 years. Only half of the included articles provided baseline fasting glucose concentrations, which ranged from $5.0 \mathrm{mmol} / \mathrm{L}$ to $10.3 \mathrm{mmol} / \mathrm{L}$.

Table 1. Basic characteristics of the included studies.

\begin{tabular}{|c|c|c|c|c|c|c|c|c|c|}
\hline First Author (Year) & Country & $\begin{array}{c}\text { Diabetes } \\
\text { Type }\end{array}$ & $N$ & $N$ Int. & $N$ Con. & $\begin{array}{c}\text { Gender } \\
\text { Ratio (F:M) }\end{array}$ & BMI & $\begin{array}{c}\text { Average } \\
\text { Age (Year) }\end{array}$ & $\begin{array}{c}\text { FBG } \\
(\mathrm{mmol} / \mathrm{L})\end{array}$ \\
\hline Jenkins, D.J (2008) [27] & Canada & T2DM & 210 & 106 & 104 & 0.6 & 30.9 & 60.5 & NS \\
\hline Turner-McGrievy (2011) [28] & USA & T2DM & 99 & 49 & 50 & 1.5 & 34.8 & 55.2 & NS \\
\hline Ebbeling, C.B (2003) [29] & USA & adiposity & 14 & 7 & 7 & 2.2 & 36.0 & 16.1 & NS \\
\hline Wolever, T.M (2008) [30] & Canada & $\mathrm{T} 2 \mathrm{DM}$ & 162 & 56 & 106 & 1.2 & 31.0 & 59.9 & 7.4 \\
\hline Wolever, T.M (2008) [31] & Canada & T2DM & 135 & 46 & 89 & 1.2 & 31.0 & 59.7 & 7.3 \\
\hline Malin, S.K (2012) [32] & USA & MetS & 21 & 11 & 10 & 0.9 & 35.5 & 66.2 & 8.0 \\
\hline Kelly, K.R (2011) [33] & USA & adiposity & 28 & 13 & 15 & 1.2 & 34.2 & 66.0 & 5.9 \\
\hline Mulya, A (2017) [15] & USA & adiposity & 19 & 9 & 10 & 0.9 & 34.0 & 64.0 & 5.5 \\
\hline Osella, A.R (2018) [34] & USA & MetS & 231 & 55 & 176 & 0.7 & NS & 57.6 & NS \\
\hline Gomes, J.M (2017) [35] & Brazil & T2DM & 20 & 10 & 10 & 1.0 & 29.2 & 42.4 & 8.2 \\
\hline Solomon, T.P (2009) [36] & USA & adiposity & 32 & 15 & 17 & 1.1 & 33.8 & 66.0 & 5.6 \\
\hline Fraser, A (2008) [37] & Israel & $\mathrm{T} 2 \mathrm{DM}$ & 201 & 73 & 128 & 1.5 & 31.4 & 56.0 & 10.3 \\
\hline Visuthranukul, C (2015) [38] & Thailand & adiposity & 52 & 25 & 27 & 0.5 & 33.6 & 12.0 & 5.0 \\
\hline Jenkins, D.J (2011) [39] & Canada & $\mathrm{T} 2 \mathrm{DM}$ & 152 & 79 & 73 & 0.6 & 30.5 & 61.5 & NS \\
\hline Pavithran, N (2020) [40] & India & T2DM & 36 & 18 & 18 & 0.7 & 27.0 & 52.0 & NS \\
\hline Solomon, T.P (2013) [41] & USA & adiposity & 20 & 10 & 10 & 1.2 & 35.0 & 65.0 & 5.9 \\
\hline Fabricatore, A.N (2011) [42] & USA & T2DM & 79 & 40 & 39 & 3.9 & 36.3 & 52.7 & NS \\
\hline Argiana, V (2014) [43] & Greece & T2DM & 58 & 28 & 30 & 1.1 & 32.5 & 62.2 & NS \\
\hline Li, D (2014) [44] & China & T2DM & 54 & 36 & 18 & 0.6 & 24.3 & 56.0 & 6.8 \\
\hline Mirza, N.M (2011) [45] & USA & adiposity & 88 & 45 & 43 & 0.9 & 29.5 & 12.2 & NS \\
\hline $\mathrm{Hu}, \mathrm{Z} . \mathrm{G}(2014)[16]$ & China & GDM & 140 & 66 & 74 & All famale & NS & 30.0 & 5.0 \\
\hline Heilbronn, L.K (2002) [17] & Australia & T2DM & 45 & 24 & 21 & 1.0 & 33.8 & 56.7 & 7.0 \\
\hline Basharat, S (2018) [46] & Pakistan & adiposity & 74 & 38 & 36 & All famale & 31.4 & 27.0 & NS \\
\hline Abete, I (2008) [14] & Spain & adiposity & 32 & 16 & 16 & 0.8 & 32.5 & 36.0 & NS \\
\hline
\end{tabular}

Int. = Intervention group; Con. = Control group; T2DM = type 2 diabetes mellitus; MetS = metabolic syndrome $\mathrm{GDM}=$ gestational diabetes mellitus; $\mathrm{NS}=$ not stated; FBG = fasting blood glucose. RCT-related characteristics of the included studies.

Table 2 shows the RCT-related characteristics and results of the quality evaluation of the included studies. The durations of the studies ranged from 3 months to 4 years and the durations of the interventions ranged from 5 days to 1 year. Most of the articles did not state the method of randomization used, but four were randomized using random numbers, two were randomized by subject ID, and two were randomized using opaque envelopes. Only five of the 24 studies used blinding and six used an energy restriction method. The diet of the intervention group was an LGID, except in one study, in which it was a low-GL diet. The mean GI of the diet in the intervention group was 36.1, which met the requirements for a low-GI diet [45]. The control diets consisted of the American Diabetes Association (ADA) Diet, a Mediterranean diet (Med-D), a modified Mediterranean Diet (MMD), a high-GI diet (HGID), a low-fat diet (LFD), a low-GI Mediterranean diet (LGIMD), a low-carbohydrate diet (LCHOD), a high-cereal fiber diet (HCFD), a routine diet (RD), or a high-GL diet (HGLD). Fraser et al. used MMD and the ADA Diet as dual controls [37], and Osela et al. used Med-D, LGIMD, and RD as triple controls [34]. In two of the studies, HGID and LCHOD were consumed by the control group [30,31]. The GIs of the diets consumed by the intervention groups ranged from 35.8 to 69.6 , and the GIs of five of the studies were $>55$, which is consistent with a medium-GI diet. The GIs of the control diets were between 59 and 83.5, all of which were medium or high GIs. The percentage of total energy yielded by the carbohydrates ( $\mathrm{CHO} \%$ ) ranged from $44 \%$ to $59.8 \%$ in the intervention group and $42.7 \%$ to $60.8 \%$ in the control group. 
Table 2. RCT-related characteristics of the included studies.

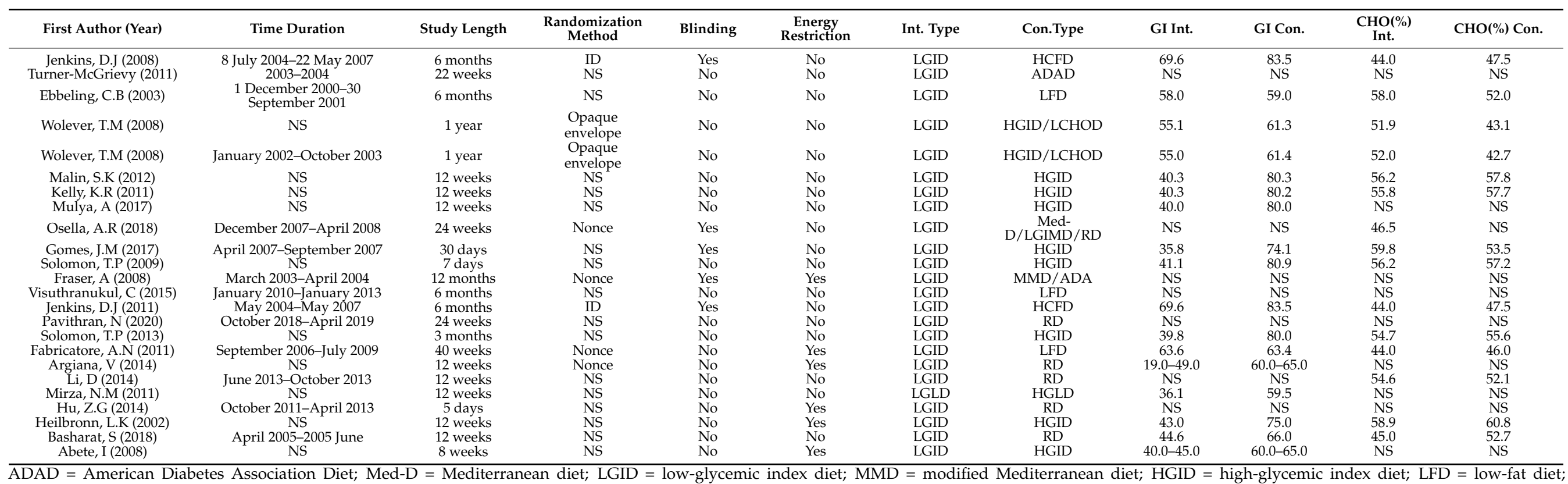

LGIMD = low-glycemic index Mediterranean diet; $L C H O D=$ low-carbohydrate diet; HCFD = high-cereal fiber diet; RD = routine diet; LGLD = low-glycemic load diet; HGLD = high-glycemic load diet. 


\subsection{Quality of the Included Studies}

The quality of the included studies was determined with reference to the Cochrane Collaboration Randomized Trials Bias Assessment tool [25]. The overall quality assessment of the included studies was "unclear risk" (Figure 2). Only one of the included studies was rated as low risk; the others were rated as unclear risk.

\subsection{Body Mass}

Eleven studies aimed to determine the effect of LGID interventions on body mass. We conducted a meta-analysis of the data after categorization according to the duration of the intervention (Figure 3). We found that a 7-day intervention had no significant effect on body mass; therefore, this was not included in the analysis [36]. Owing to the heterogeneity of the study data, a random-effects model was adopted. The combined data from all the included studies indicated that the LGIDs were superior to the other diets with respect to their body mass-lowering effect $\left(\mathrm{I}^{2}=87 \%\right)$. The overall effect size (MD) was $-2.65(95 \% \mathrm{CI}$ : $-4.35,-0.95)$. Categorization of the data according to the duration of the intervention revealed a slight reduction in the heterogeneity of the studies when the duration was $\geq 24$ weeks in length $\left(\mathrm{I}^{2}=77 \%\right)$.

\section{5. $B M I$}

The relationship between BMI and an LGID was evaluated using data from 10 studies. One of the studies utilized a 7-day intervention, which we did not think would be sufficient to cause a significant change in BMI. Therefore, this study was not included in the metaanalysis [32]. The heterogeneity of the studies was very clear; therefore, a random-effects model was adopted $\left(\mathrm{I}^{2}=72 \%\right.$; Figure 4$)$. Overall, an LGID was found to be beneficial for BMI (MD $=-0.72 ; 95 \% \mathrm{CI}:-1.18,-0.27)$. A meta-analysis was then performed on the data after categorization according to the duration of the intervention. After a 24-week intervention, the heterogeneity of the studies was low and the intervention was shown to reduce $\mathrm{BMI}\left(\mathrm{I}^{2}=0 \%, \mathrm{MD}=-2.02,95 \% \mathrm{CI}:-3.05,-0.98\right)$. When the intervention lasted for 12 weeks, the analysis also showed that an LGID was superior to the other diets at reducing $\mathrm{BMI}$, although there was significant heterogeneity $\left(\mathrm{I}^{2}=71 \%, \mathrm{MD}=-0.55,95 \% \mathrm{CI}\right.$ : $-1.01,-0.10)$.

Random sequence genetation selection bias

Allocation concealment selection bias

Blinding of outcome assessment detection bias

Incomplete outcome data attrition bias

Selective reporting reporting bias

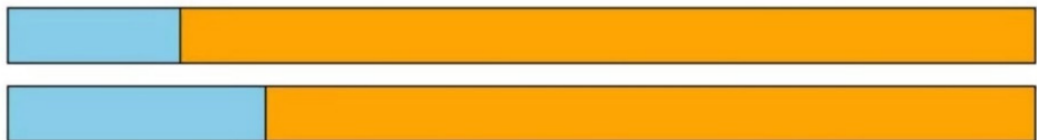

\section{Blinding of participants and personnel performance bias}

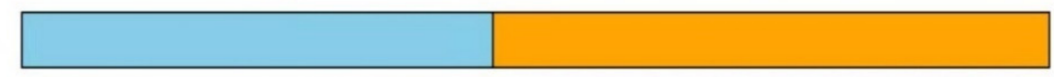

.
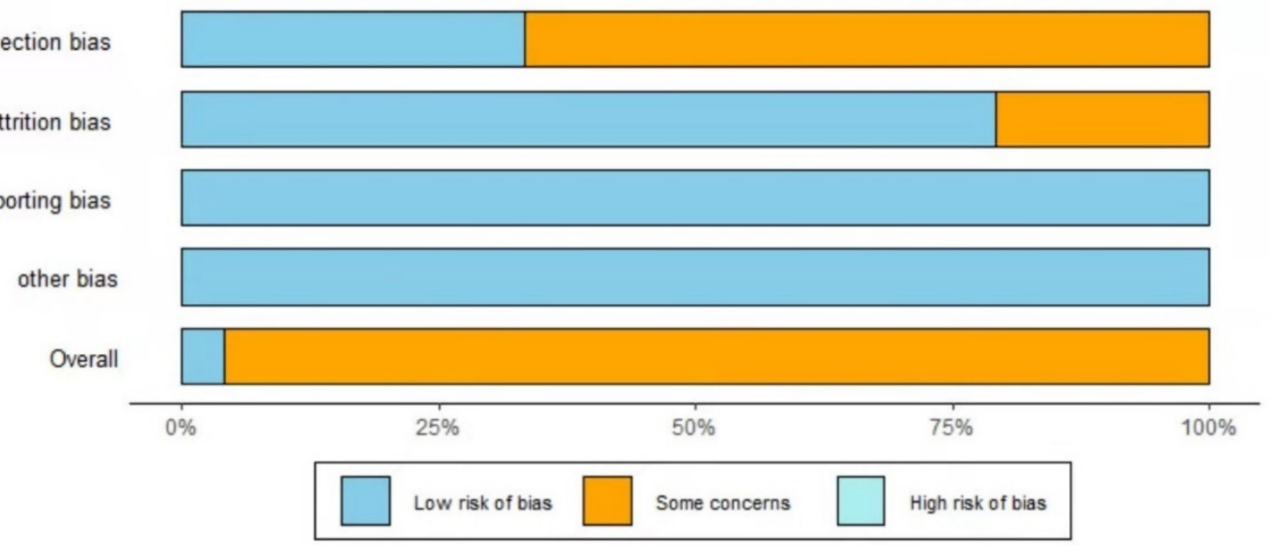

(A)

Figure 2. Cont. 


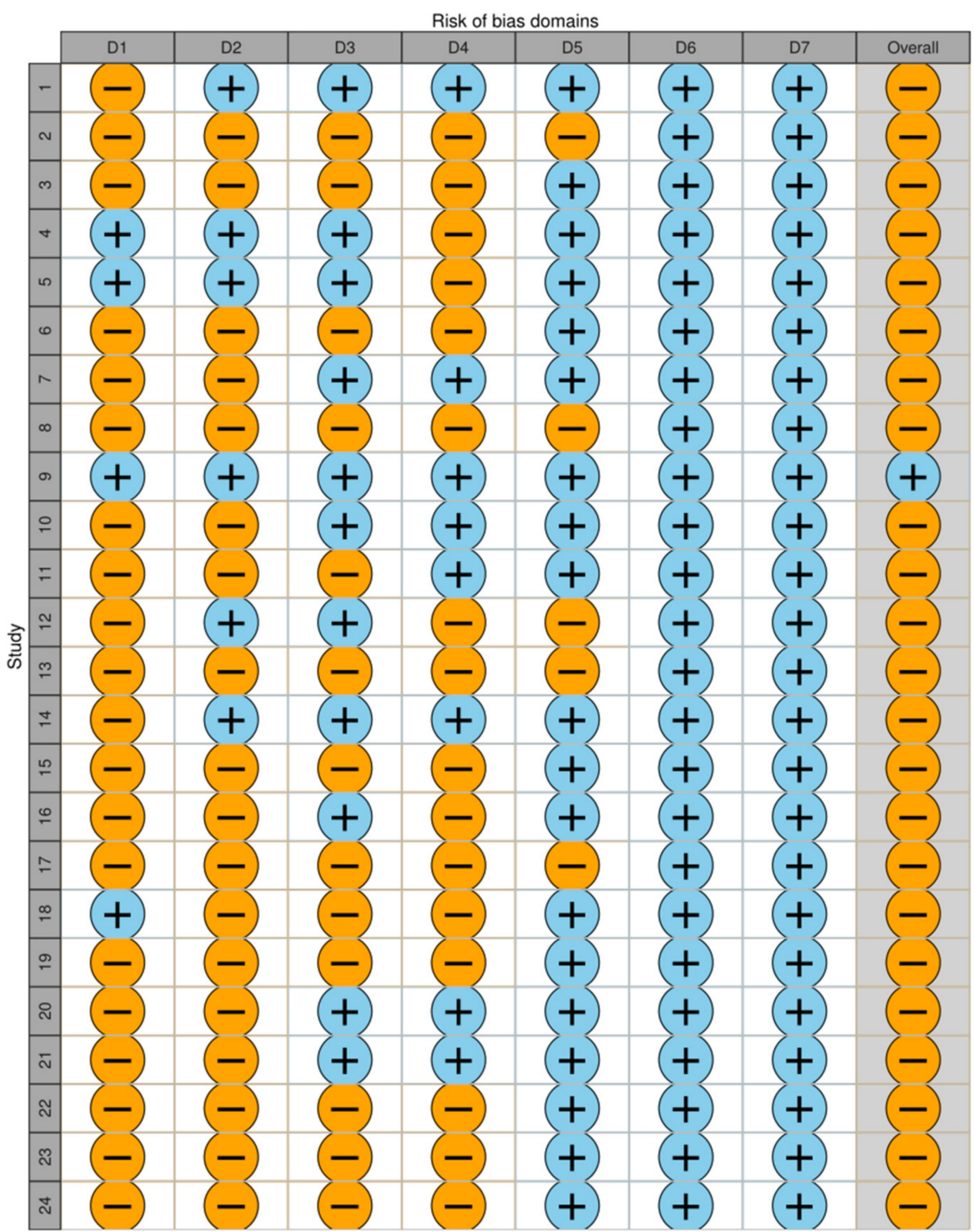

(B)

Figure 2. Risks of bias for the included studies. (A): Risk of bias graph; (B): risk of bias summary. D1 = Random sequence generation (selection bias), D2 = Allocation concealment (selection bias), D3 = Blinding of participants and personnel (performance bias), D4 = Blinding of outcome assessment (detection bias), D5 = Incomplete outcome data (attrition bias), D6 = Selective reporting (reporting bias), D7 $=$ other bias. Sky blue $(+)=$ low risk of bias, Orange $(-)=$ unclear risk of bias, Turquoise $(x)=$ high risk of bias.

\section{6. $F B G$}

FBG was measured in eight studies. We performed a meta-analysis of data from these studies, categorized according to the duration of the intervention (Figure 5). Because of the significant heterogeneity of the studies $\left(\mathrm{I}^{2}=91 \%\right)$, we used a random-effects model. Overall, the analysis showed that an LGID was superior to a control diet at reducing FBG $(\mathrm{MD}=-0.26,95 \% \mathrm{CI}:-0.43,-0.08)$. The subgroup analysis showed that when the duration of the intervention was $\leq 7$ days, there was no significant difference in the change in FBG between the LGID and control groups (MD $=-0.04 ; 95 \% \mathrm{CI}$ : $-0.15,-0.06$ ). However, when the intervention lasted $\geq 30$ days, the LGIDs were found to be superior to the control diets at reducing FBG $(\mathrm{MD}=-0.34,95 \% \mathrm{CI}:-0.55,-0.12)$. 


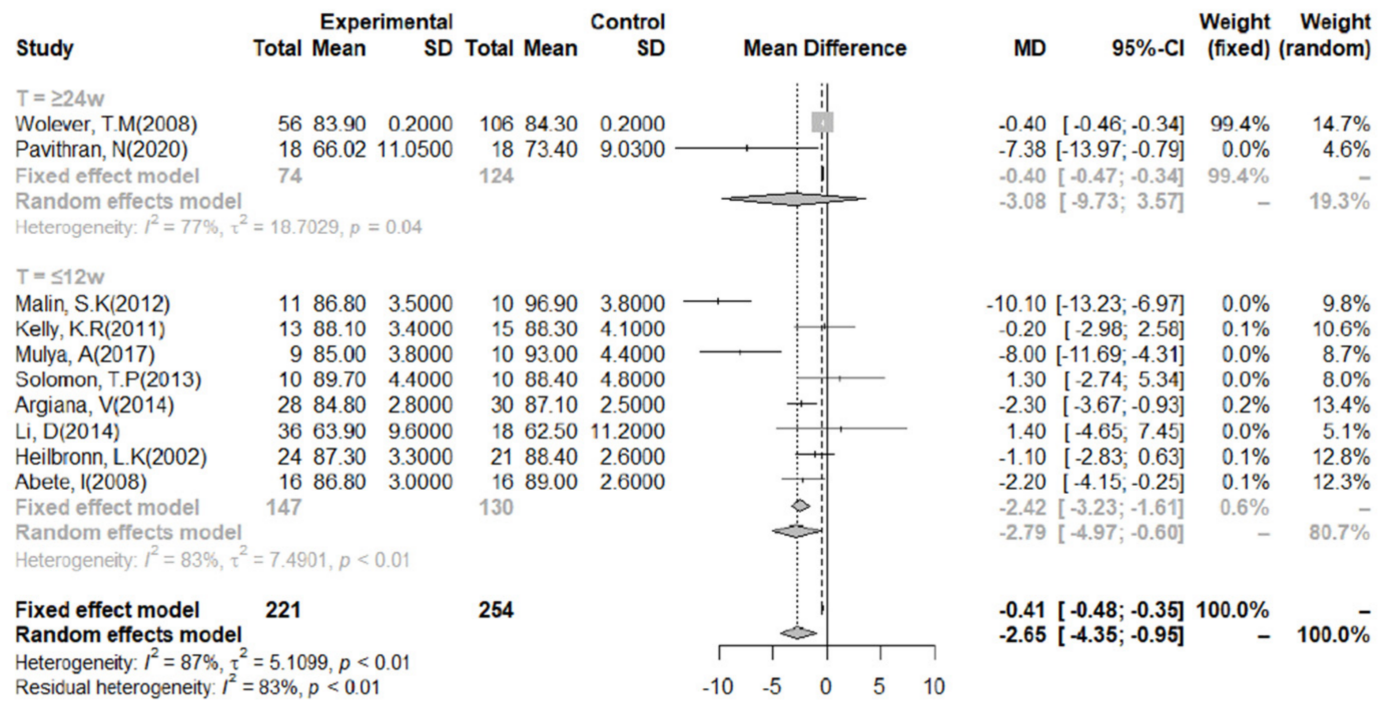

Figure 3. Meta-analysis of the effect of a low-glycemic index diet on body mass, according to the duration of the intervention. A random-effects model and mean difference analysis were used.

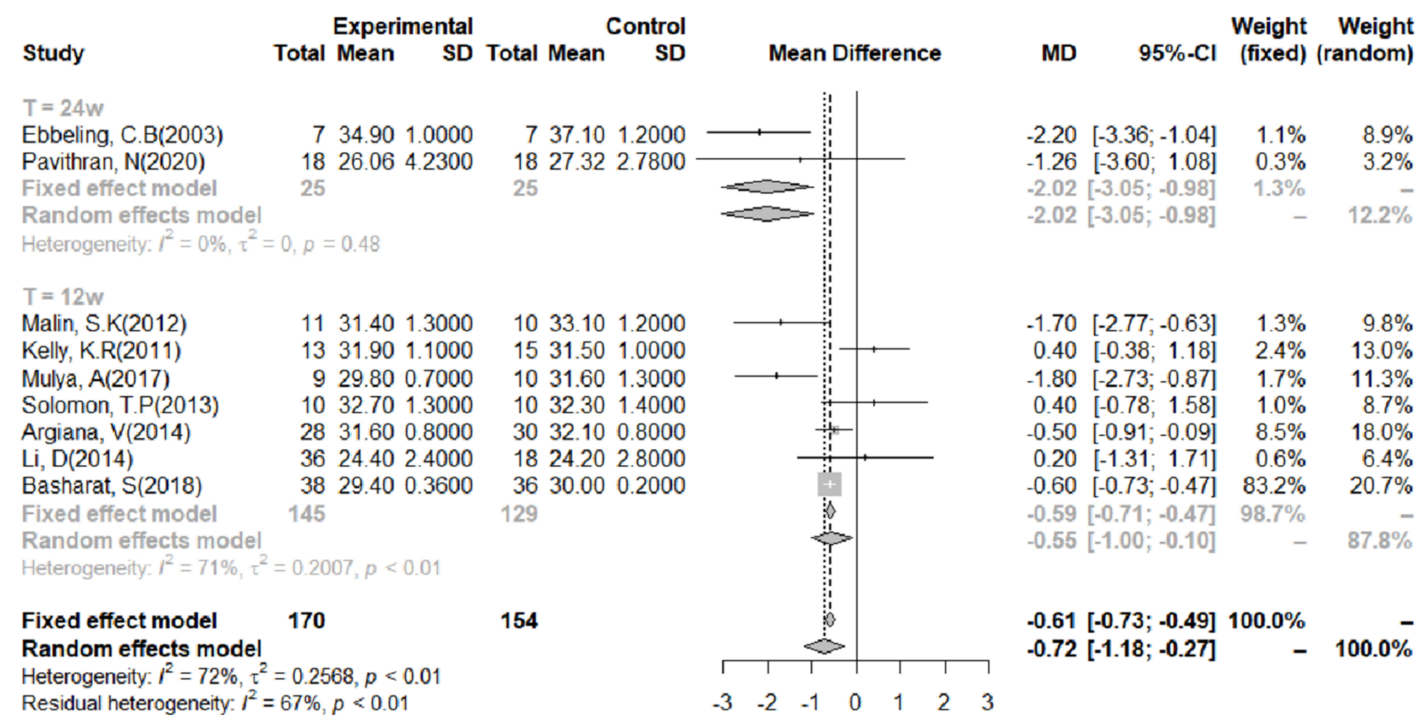

Figure 4. Meta-analysis of the effect of a low-glycemic index diet on body mass index, using data categorized according to the duration of the intervention. A random-effects model and mean difference analysis were used.

\section{7. $\mathrm{HbA1c} \%$}

Eight studies reported $\mathrm{HbA} 1 \mathrm{c} \%$ concentrations (Figure 6), and there was a high level of heterogeneity in these studies $\left(\mathrm{I}^{2}=94 \%\right)$. Overall, the effect of LGIDs on $\mathrm{HbA1c} \%$ was statistically significant $(\mathrm{MD}=-0.30,95 \% \mathrm{CI}=-0.49,-0.10)$. Meta-analysis of the data, categorized according to the duration of the intervention, showed that when it lasted for $\geq 24$ weeks, the LGIDs tended to be superior to other diets at reducing $\mathrm{HbA1c} \%$, although the difference was not statistically significant $(\mathrm{MD}=-0.58,95 \% \mathrm{CI}=-1.62,0.46)$. 


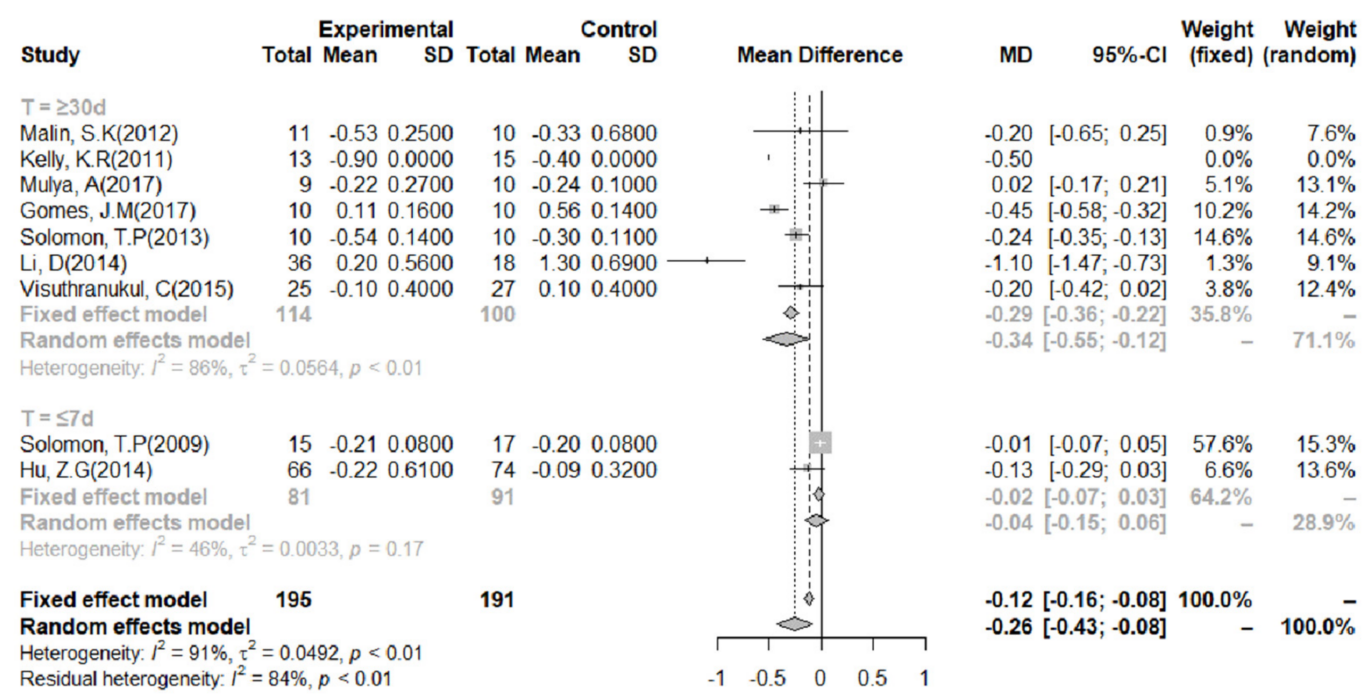

Figure 5. Meta-analysis of the effect of a low-glycemic index diet on fasting blood glucose concentration, categorized according to the duration of the study. A random-effects model and mean difference analysis were used.

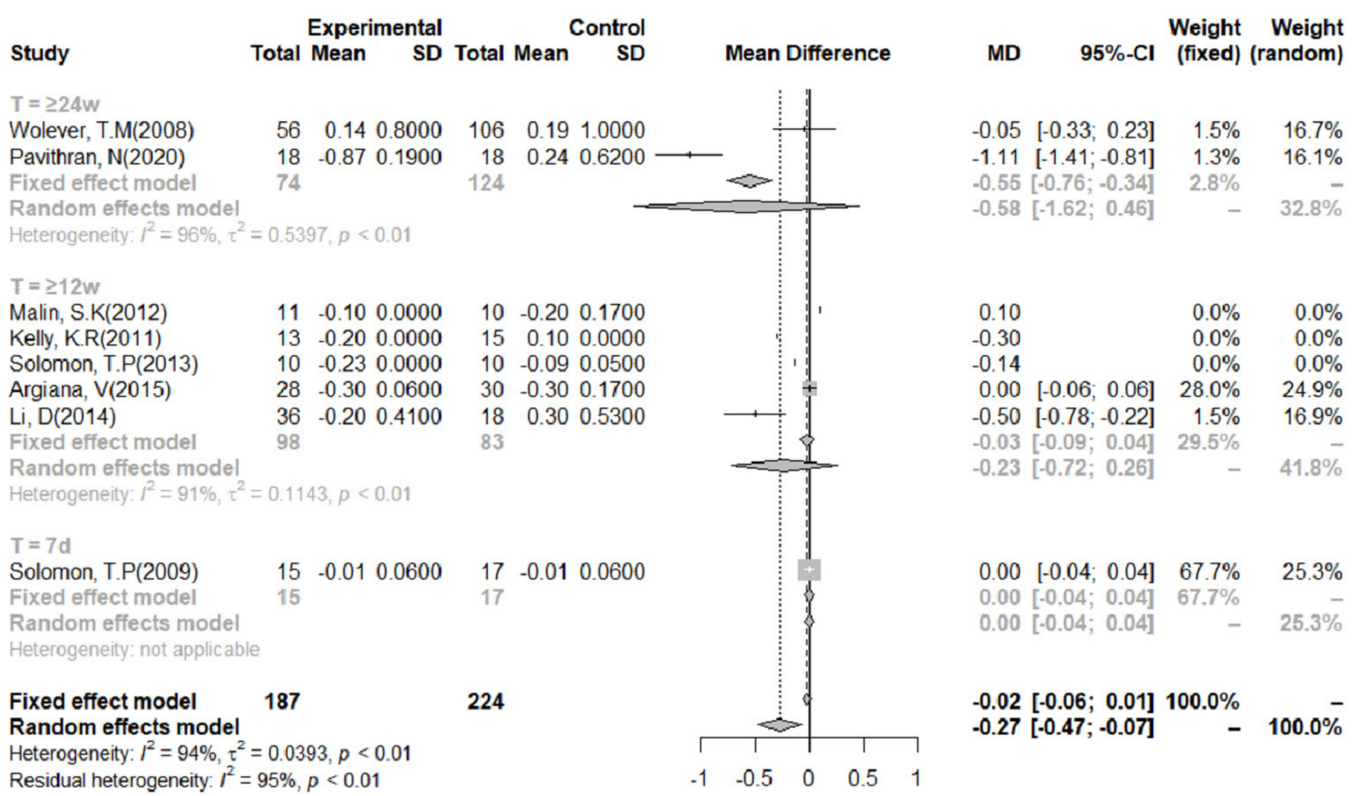

Figure 6. Meta-analysis of the effect of a low-glycemic index diet on glycated hemoglobin (HbA1c\%), according to the duration of the intervention. A random-effects model and mean difference analysis were used.

\section{Discussion}

The present systematic review and meta-analysis show that an LGID is superior to a number of other diets in the control of body mass, which is consistent with the results of previous studies [15,32,40,43,47]. Furthermore, stratified analyses of the duration of the intervention showed that studies with a duration of $\geq 24$ weeks generated more consistent results and larger reductions in body mass and BMI.

A previous systematic review and meta-analysis of RCTs performed in children, adolescents, or adults suggested that the effect of LGIDs on body mass takes at least 4 weeks to manifest [48]. Another meta-analysis of long-term ( $\geq 6$ months) LGID/LGLD interventions showed that these reduce body mass by $0.62 \mathrm{~kg}$ more than a high-GI or other 
diet. In addition, it was shown that a long-term LGID/LGLD intervention is beneficial for the control of C-reactive protein and fasting insulin concentrations [21]. However, these two meta-analyses only included studies of overweight or obese people [21,48]. A study conducted in postpartum women with obesity showed that 12 weeks of consumption of an LGID reduces body mass and BMI, without reducing fat mass or muscle mass, compared to a control diet [46]. In a further RCT, a low-GL diet or control diet was assigned to 86 overweight or obesity adults. The trial was divided into two phases: the first was a 12-week initial weight-loss phase and the second was a 24-36-week weight maintenance phase. During the first stage, the weight loss-inducing effect of the low-GL diet was significantly better than that of the control diet, whereas during the second stage, there was no difference in weight loss between the two groups [49]. To gain further insight into the effects of such diets, more long-term RCT studies of LGID interventions are required.

We have also shown that an LGID is more effective than HGID or other diets at controlling FBG and HbA1c, as previously shown [19,50,51]. Subgroup analyses showed that LGID interventions of $\geq 4$ weeks reduced FBG and $\mathrm{HbA} 1 \mathrm{c} \%$ more substantially than an HGID or other diet. Conversely, a 12-month RCT conducted in patients with type 2 diabetes did not show that LGID is better than a low-carbohydrate diet or an HGID at controlling $\mathrm{HbA1c}$ [31]. Previous studies have shown that postprandial hyperglycemia may account for $70 \%$ of the total daytime hyperglycemia and that the contribution of postprandial blood glucose fluctuations varies as blood glucose control deteriorates, which may explain the inconsistent relationship identified between a low-GI diet and $\mathrm{HbA} 1 \mathrm{c}$ in previous studies [11]. The results of the present systematic review are consistent with those of a systematic review performed in 2018, which showed that an LGID is more effective at controlling $\mathrm{HbA} 1 \mathrm{c}$ and FBG than an HGID or other diets. However, this previous review focused on adults with type 2 diabetes and did not involve an analysis that considered the duration of the intervention [19]. A study of LGID in children with diabetes showed that it is superior to a control diet at controlling $\mathrm{HbA1c}$ and also that the number of children consuming an LGID that achieve an acceptable $\mathrm{HbA} 1 \mathrm{c}$ after 12 month is twice that of the number of children consuming a control diet [52]. Therefore, more RCT studies of $>4$ weeks' duration should be conducted with FBG and HbA1c as outcomes, in order to collect more robust data in this field.

There was high heterogeneity in the studies that assessed all of $\mathrm{HbA1c} \%, \mathrm{FBG}$, body mass, and BMI, which may suggest that previous studies of low-GI diets have not been well standardized. Food GI and the blood glucose response are also affected by the cooking method and time, properties of starch, particle size, $\mathrm{pH}$, fiber content, fat content, and protein content, which can have significant effects on study outcomes [53]. One study of the effect of a low-GI diet on diabetes showed that it significantly reduced FBG vs. the habitual diet, a 'healthy' diet, an anti-hypertensive diet, and a low-carbohydrate diet [54]. However, because only 16 studies were included in the present analyses but eight different control diets were used, it is not possible to analyze the data according to the identity of the control diet. Furthermore, heterogeneity may be introduced because of differences in the classification of an LGID and an HGID in the literature [12,55]. In addition, most previous reports did not describe the proportions of carbohydrate, fat, and protein present in the diets used. This may explain why there has been inconsistency and controversy over the use of GI as a guide for the selection of foods by people with diabetes, and also why previous studies of the effects of an LGID on health and health-related outcomes have generated mixed results [12]. The Chinese Medical Nutrition Treatment Guidelines for Overweight/Obesity (2021) include an LGID as one of the diets that are suitable for the treatment of overweight and obesity and indicates that such a diet is beneficial with respect to weight loss, satiety, and insulin resistance, which is consistent with the results of the present study. However, the guidelines do not clearly define an LGID, nor do they specify appropriate ranges for the contents of the three macronutrients in an LGID [56]. Therefore, an explicit definition of an LGID is urgently required, so that more comprehensive and repeatable research regarding the use of LGIDs can be performed. 
An important reason for claiming that LGID is beneficial to overall health is that LGID may help with weight control because it can promote satiety. Another important reason is that LGID can stimulate a sustained and small release of insulin by slowly releasing glucose into the bloodstream, causing a slow increase in blood glucose and insulin concentrations over time, flattening the postprandial blood glucose and insulin curves [48,57]. It is worth noting that in addition to body weight and BMI, there are more indicators, such as resting energy expenditure, body fat percentage and cholesterol, etc., which can indicate the effect and cause of weight loss, as well as other health effects. A randomized controlled trial study conducted in obese or overweight people found that LGID can promote resting and total energy expenditure [58]. A previous review showed that a LGID may reduce highdensity-lipoprotein cholesterol and triacylglycerol levels [59]. Unfortunately, these metrics are relatively expensive and difficult to obtain. Therefore, there are currently relatively few articles using indicators such as resting energy and body fat percentage. In the future, further research can be carried out based on the above indicators.

\section{Strengths and Limitations of the Study}

We have used a systematic review and meta-analysis to provide more comprehensive evidence of the positive effects of low-GI diets on body mass, BMI, FBG, and HbA1c\% than obtained previously. All the included studies were RCTs without a unilateral bias and the quality of evidence obtained was assessed using the Cochrane Collaboration tool. Seventeen RCTs were selected using the PICOS principles. None of these trials were rated as having a significant risk of bias and there was no evidence of publication bias.

There were several limitations to the present study. First, relatively few studies were included in the meta-analysis and the sample size of most of these was relatively small. Second, there was considerable heterogeneity in these studies, which may be associated with the large differences between studies with respect to the baseline values of parameters and the durations of the interventions. Analysis of categorized data did not significantly reduce this heterogeneity. Third, the method of data extraction was non-blinded, which represents a potential source of bias. Fourth, some linguistic bias is unavoidable, and the only reports identified were written in English. Finally, most of the constituent studies did not report their findings according to sex; therefore, we could not determine whether there was an influence of sex on the outcomes.

\section{Conclusions}

The present systematic review and meta-analysis provide evidence that an LGID is superior to an HGID or other diet for the control of body mass, BMI, FBG, and HbA1c\% in patients with one of four common metabolic diseases (obesity, metabolic syndrome, diabetes and cardiovascular disease). In particular, the meta-analysis showed that longterm compliance is associated with weight loss and a reduction in FBG. Accordingly, LGID interventions are recommended to last for at least four weeks, especially if body mass and FBG are used as outcomes.

Author Contributions: Conceptualization, C.N. and M.Y.; methodology, C.N.; formal analysis, C.N and Q.J.; investigation, C.N. and Q.J.; data curation, C.N. and Q.J.; writing—original draft preparation, C.N.; writing - review and editing, M.Y., G.D. and X.W.; supervision, M.Y.; project administration, M.Y. and C.N.; funding acquisition, M.Y., G.D. and X.W. All authors have read and agreed to the published version of the manuscript.

Funding: This research was funded by the Fundamental Research Fund for the Zhejiang Provincial Universities (grant number 2021XZZX029), the Key Laboratory of Intelligent Preventive Medicine of Zhejiang Province (grant number 2020E10004), the Leading Innovative and Entrepreneur Team Introduction Program of Zhejiang (grant number 2019R01007), and the Key Research and Development Program of Zhejiang Province (grant number 2020C03002).

Institutional Review Board Statement: Not applicable.

Informed Consent Statement: Not applicable. 
Data Availability Statement: Not applicable, due to being systematic review with meta-analyses. All data is available in primary studies.

Acknowledgments: We thank Mark Cleasby, PhD from Liwen Bianji (Edanz) (www.liwenbianji.cn, accessed on 14 December 2021) for editing the language of a draft of this manuscript.

Conflicts of Interest: The authors declare no conflict of interest.

\section{References}

1. Roth, G.A.; Mensah, G.A.; Johnson, C.O.; Addolorato, G.; Ammirati, E.; Baddour, L.M.; Barengo, N.C.; Beaton, A.Z.; Benjamin, E.J.; Benziger, C.P.; et al. Global Burden of Cardiovascular Diseases and Risk Factors, 1990-2019: Update From the GBD 2019 Study. J. Am. Coll. Cardiol. 2020, 76, 2982-3021. [CrossRef] [PubMed]

2. GBD 2019 Diseases and Injuries Collaborators. Global burden of 369 diseases and injuries in 204 countries and territories, 1990-2019: A systematic analysis for the Global Burden of Disease Study 2019. Lancet 2020, 396, 1204-1222. [CrossRef]

3. Bommer, C.; Sagalova, V.; Heesemann, E.; Manne-Goehler, J.; Atun, R.; Bärnighausen, T.; Davies, J.; Vollmer, S. Global Economic Burden of Diabetes in Adults: Projections From 2015 to 2030. Diabetes Care 2018, 41, 963-970. [CrossRef]

4. Saklayen, M.G. The Global Epidemic of the Metabolic Syndrome. Curr. Hypertens. Rep. 2018, 20, 12. [CrossRef]

5. Kelly, T.; Yang, W.; Chen, C.S.; Reynolds, K.; He, J. Global burden of obesity in 2005 and projections to 2030. Int. J. Obes. 2008, 32, 1431-1437. [CrossRef]

6. Kim, K.H.; Lee, M.S. Autophagy_A key player in cellular and body metabolism. Nat. Rev. Endocrinol. 2014, 10, 322-337. [CrossRef]

7. Wilson, P.W.; D'Agostino, R.B.; Sullivan, L.; Parise, H.; Kannel, W.B. Overweight and obesity as determinants of cardiovascular risk: The Framingham experience. Arch. Intern. Med. 2002, 162, 1867-1872. [CrossRef] [PubMed]

8. Jenkins, D.J.; Wolever, T.M.; Taylor, R.H.; Barker, H.; Fielden, H.; Baldwin, J.M.; Bowling, A.C.; Newman, H.C.; Jenkins, A.L.; Goff, D.V. Glycemic index of foods: A physiological basis for carbohydrate exchange. Am. J. Clin. Nutr. 1981, 34, 362-366. [CrossRef]

9. Eleazu, C.O. The concept of low glycemic index and glycemic load foods as panacea for type 2 diabetes mellitus; prospects, challenges and solutions. Afr. Health Sci. 2016, 16, 468-479. [CrossRef] [PubMed]

10. Vega-López, S.; Venn, B.J.; Slavin, J.L. Relevance of the Glycemic Index and Glycemic Load for Body Weight, Diabetes, and Cardiovascular Disease. Nutrients 2018, 10, 1361. [CrossRef] [PubMed]

11. Chiu, C.J.; Taylor, A. Dietary hyperglycemia, glycemic index and metabolic retinal diseases. Prog. Retin. Eye Res. 2011, 30, 18-53. [CrossRef]

12. Jenkins, D.J.; Kendall, C.W.; Augustin, L.S.; Franceschi, S.; Hamidi, M.; Marchie, A.; Jenkins, A.L.; Axelsen, M. Glycemic index: Overview of implications in health and disease. Am. J. Clin. Nutr. 2002, 76, 266S-273S. [CrossRef]

13. Devlin, B.L.; Parr, E.B.; Radford, B.E.; Hawley, J.A. Lower nocturnal blood glucose response to a potato-based mixed evening meal compared to rice in individuals with type 2 diabetes. Clin. Nutr. 2021, 40, 2200-2209. [CrossRef] [PubMed]

14. Abete, I.; Parra, D.; Martinez, J.A. Energy-restricted diets based on a distinct food selection affecting the glycemic index induce different weight loss and oxidative response. Clin. Nutr. 2008, 27, 545-551. [CrossRef]

15. Mulya, A.; Haus, J.M.; Solomon, T.P.J.; Kelly, K.R.; Malin, S.K.; Rocco, M.; Barkoukis, H.; Kirwan, J.P. Exercise training-induced improvement in skeletal muscle PGC-1alpha-mediated fat metabolism is independent of dietary glycemic index. Obesity 2017, 25, 721-729. [CrossRef] [PubMed]

16. Hu, Z.G.; Tan, R.S.; Jin, D.; Li, W.; Zhou, X.Y. A low glycemic index staple diet reduces postprandial glucose values in Asian women with gestational diabetes mellitus. J. Investig. Med. 2014, 62, 975-979. [CrossRef]

17. Heilbronn, L.K.; Noakes, M.; Clifton, P.M. The effect of high- and low-glycemic index energy restricted diets on plasma lipid and glucose profiles in type 2 diabetic subjects with varying glycemic control. J. Am. Coll. Nutr. 2002, 21, 120-127. [CrossRef]

18. Livesey, G.; Taylor, R.; Livesey, H.F.; Buyken, A.E.; Jenkins, D.J.A.; Augustin, L.S.A.; Sievenpiper, J.L.; Barclay, A.W.; Liu, S.; Wolever, T.M.S.; et al. Dietary Glycemic Index and Load and the Risk of Type 2 Diabetes: A Systematic Review and Updated Meta-Analyses of Prospective Cohort Studies. Nutrients 2019, 11, 1280. [CrossRef] [PubMed]

19. Ojo, O.; Ojo, O.O.; Adebowale, F.; Wang, X.H. The Effect of Dietary Glycaemic Index on Glycaemia in Patients with Type 2 Diabetes: A Systematic Review and Meta-Analysis of Randomized Controlled Trials. Nutrients 2018, 10, 373. [CrossRef]

20. Thomas, D.; Elliott, E.J. Low glycaemic index, or low glycaemic load, diets for diabetes mellitus. Cochrane Database Syst. Rev. 2009, 2009, Cd006296. [CrossRef]

21. Schwingshackl, L.; Hoffmann, G. Long-term effects of low glycemic index/load vs. high glycemic index/load diets on parameters of obesity and obesity-associated risks: A systematic review and meta-analysis. Nutr. Metab. Cardiovasc. Dis. NMCD 2013, 23, 699-706. [CrossRef]

22. Askari, M.; Dehghani, A.; Abshirini, M.; Raeisi, T.; Alizadeh, S. Glycemic index, but not glycemic load, is associated with an increased risk of metabolic syndrome: Meta-analysis of observational studies. Int. J. Clin. Pract. 2021, 75, e14295. [CrossRef]

23. Mirrahimi, A.; de Souza, R.J.; Chiavaroli, L.; Sievenpiper, J.L.; Beyene, J.; Hanley, A.J.; Augustin, L.S.; Kendall, C.W.; Jenkins, D.J Associations of glycemic index and load with coronary heart disease events: A systematic review and meta-analysis of prospective cohorts. J. Am. Heart Assoc. 2012, 1, e000752. [CrossRef] 
24. Liberati, A.; Altman, D.G.; Tetzlaff, J.; Mulrow, C.; Gotzsche, P.C.; Ioannidis, J.P.; Clarke, M.; Devereaux, P.J.; Kleijnen, J.; Moher, D. The PRISMA statement for reporting systematic reviews and meta-analyses of studies that evaluate health care interventions: Explanation and elaboration. PLoS Med. 2009, 6, e1000100. [CrossRef] [PubMed]

25. Higgins, J.P.; Altman, D.G.; Gotzsche, P.C.; Juni, P.; Moher, D.; Oxman, A.D.; Savovic, J.; Schulz, K.F.; Weeks, L.; Sterne, J.A.; et al. The Cochrane Collaboration's tool for assessing risk of bias in randomised trials. BMJ 2011, 343, d5928. [CrossRef]

26. Higgins, J.P.; Thompson, S.G.; Deeks, J.J.; Altman, D.G. Measuring inconsistency in meta-analyses. BMJ 2003, 327, 557-560. [CrossRef] [PubMed]

27. Jenkins, D.J.; Kendall, C.W.; McKeown-Eyssen, G.; Josse, R.G.; Silverberg, J.; Booth, G.L.; Vidgen, E.; Josse, A.R.; Nguyen, T.H.; Corrigan, S.; et al. Effect of a low-glycemic index or a high-cereal fiber diet on type 2 diabetes: A randomized trial. JAMA 2008, 300, 2742-2753. [CrossRef]

28. Turner-McGrievy, G.M.; Jenkins, D.J.; Barnard, N.D.; Cohen, J.; Gloede, L.; Green, A.A. Decreases in dietary glycemic index are related to weight loss among individuals following therapeutic diets for type 2 diabetes. J. Nutr. 2011, 141, 1469-1474. [CrossRef] [PubMed]

29. Ebbeling, C.B.; Leidig, M.M.; Sinclair, K.B.; Hangen, J.P.; Ludwig, D.S. A reduced-glycemic load diet in the treatment of adolescent obesity. Arch. Pediatrics Adolesc. Med. 2003, 157, 773-779. [CrossRef]

30. Wolever, T.M.; Gibbs, A.L.; Mehling, C.; Chiasson, J.L.; Connelly, P.W.; Josse, R.G.; Leiter, L.A.; Maheux, P.; Rabasa-Lhoret, R.; Rodger, N.W.; et al. The Canadian Trial of Carbohydrates in Diabetes (CCD), a 1-y controlled trial of low-glycemic-index dietary carbohydrate in type 2 diabetes: No effect on glycated hemoglobin but reduction in C-reactive protein. Am. J. Clin. Nutr. 2008, 87, 114-125. [CrossRef]

31. Wolever, T.M.; Mehling, C.; Chiasson, J.L.; Josse, R.G.; Leiter, L.A.; Maheux, P.; Rabasa-Lhoret, R.; Rodger, N.W.; Ryan, E.A. Low glycaemic index diet and disposition index in type 2 diabetes (the Canadian trial of carbohydrates in diabetes): A randomised controlled trial. Diabetologia 2008, 51, 1607-1615. [CrossRef] [PubMed]

32. Malin, S.K.; Niemi, N.; Solomon, T.P.; Haus, J.M.; Kelly, K.R.; Filion, J.; Rocco, M.; Kashyap, S.R.; Barkoukis, H.; Kirwan, J.P. Exercise training with weight loss and either a high- or low-glycemic index diet reduces metabolic syndrome severity in older adults. Ann. Nutr. Metab. 2012, 61, 135-141. [CrossRef] [PubMed]

33. Kelly, K.R.; Haus, J.M.; Solomon, T.P.; Patrick-Melin, A.J.; Cook, M.; Rocco, M.; Barkoukis, H.; Kirwan, J.P. A low-glycemic index diet and exercise intervention reduces TNF(alpha) in isolated mononuclear cells of older, obese adults. J. Nutr. 2011, 141, 1089-1094. [CrossRef] [PubMed]

34. Osella, A.R.; Colaianni, G.; Correale, M.; Pesole, P.L.; Bruno, I.; Buongiorno, C.; Deflorio, V.; Leone, C.M.; Colucci, S.C.; Grano, M.; et al. Irisin Serum Levels in Metabolic Syndrome Patients Treated with Three Different Diets: A Post-Hoc Analysis from a Randomized Controlled Clinical Trial. Nutrients 2018, 10, 844. [CrossRef]

35. Gomes, J.M.G.; Fabrini, S.P.; Alfenas, R.C.G. Low glycemic index diet reduces body fat and attenuates inflammatory and metabolic responses in patients with type 2 diabetes. Arch. Endocrinol. Metab. 2017, 61, 137-144. [CrossRef]

36. Solomon, T.P.; Haus, J.M.; Kelly, K.R.; Cook, M.D.; Riccardi, M.; Rocco, M.; Kashyap, S.R.; Barkoukis, H.; Kirwan, J.P. Randomized trial on the effects of a 7-d low-glycemic diet and exercise intervention on insulin resistance in older obese humans. Am. J. Clin. Nutr. 2009, 90, 1222-1229. [CrossRef]

37. Fraser, A.; Abel, R.; Lawlor, D.A.; Fraser, D.; Elhayany, A. A modified Mediterranean diet is associated with the greatest reduction in alanine aminotransferase levels in obese type 2 diabetes patients: Results of a quasi-randomised controlled trial. Diabetologia 2008, 51, 1616-1622. [CrossRef]

38. Visuthranukul, C.; Sirimongkol, P.; Prachansuwan, A.; Pruksananonda, C.; Chomtho, S. Low-glycemic index diet may improve insulin sensitivity in obese children. Pediatric Res. 2015, 78, 567-573. [CrossRef]

39. Jenkins, D.J.; Srichaikul, K.; Kendall, C.W.; Sievenpiper, J.L.; Abdulnour, S.; Mirrahimi, A.; Meneses, C.; Nishi, S.; He, X.; Lee, S.; et al. The relation of low glycaemic index fruit consumption to glycaemic control and risk factors for coronary heart disease in type 2 diabetes. Diabetologia 2011, 54, 271-279. [CrossRef]

40. Pavithran, N.; Kumar, H.; Menon, A.S.; Pillai, G.K.; Sundaram, K.R.; Ojo, O. The Effect of a Low GI Diet on Truncal Fat Mass and Glycated Hemoglobin in South Indians with Type 2 Diabetes-A Single Centre Randomized Prospective Study. Nutrients 2020, 12, 179. [CrossRef]

41. Solomon, T.P.; Haus, J.M.; Cook, M.A.; Flask, C.A.; Kirwan, J.P. A low-glycemic diet lifestyle intervention improves fat utilization during exercise in older obese humans. Obesity 2013, 21, 2272-2278. [CrossRef]

42. Fabricatore, A.N.; Wadden, T.A.; Ebbeling, C.B.; Thomas, J.G.; Stallings, V.A.; Schwartz, S.; Ludwig, D.S. Targeting dietary fat or glycemic load in the treatment of obesity and type 2 diabetes: A randomized controlled trial. Diabetes Res. Clin. Pract. 2011, 92, 37-45. [CrossRef]

43. Argiana, V.; Kanellos, P.; Makrilakis, K.; Eleftheriadou, I.; Tsitsinakis, G.; Kokkinos, A.; Perrea, D.; Tentolouris, N. The effect of consumption of low-glycemic-index and low-glycemic-load desserts on anthropometric parameters and inflammatory markers in patients with type 2 diabetes mellitus. Eur. J. Nutr. 2015, 54, 1173-1180. [CrossRef]

44. Li, D.; Zhang, P.; Guo, H.; Ling, W. Taking a low glycemic index multi-nutrient supplement as breakfast improves glycemic control in patients with type 2 diabetes mellitus: A randomized controlled trial. Nutrients 2014, 6, 5740-5755. [CrossRef] 
45. Mirza, N.M.; Klein, C.J.; Palmer, M.G.; McCarter, R.; He, J.; Ebbeling, C.B.; Ludwig, D.S.; Yanovski, J.A. Effects of high and low glycemic load meals on energy intake, satiety and hunger in obese Hispanic-American youth. Int. J. Pediatric Obes. IJPO 2011, 6, e523-e531. [CrossRef]

46. Basharat, S.; Gilani, S.A.; Burq, A.I.; Bashir, S. Low glycaemic index diet is effective in managing weight among obese postpartum women. JPMA J. Pak. Med. Assoc. 2018, 68, 548-553. [PubMed]

47. Chiavaroli, L.; Kendall, C.W.C.; Braunstein, C.R.; Blanco Mejia, S.; Leiter, L.A.; Jenkins, D.J.A.; Sievenpiper, J.L. Effect of pasta in the context of low-glycaemic index dietary patterns on body weight and markers of adiposity: A systematic review and meta-analysis of randomised controlled trials in adults. BMJ Open 2018, 8, e019438. [CrossRef] [PubMed]

48. Zafar, M.I.; Mills, K.E.; Zheng, J.; Peng, M.M.; Ye, X.; Chen, L.L. Low glycaemic index diets as an intervention for obesity: A systematic review and meta-analysis. Obes. Rev. Off. J. Int. Assoc. Study Obes. 2019, 20, 290-315. [CrossRef]

49. Maki, K.C.; Rains, T.M.; Kaden, V.N.; Raneri, K.R.; Davidson, M.H. Effects of a reduced-glycemic-load diet on body weight, body composition, and cardiovascular disease risk markers in overweight and obese adults. Am. J. Clin. Nutr. 2007, 85, 724-734. [CrossRef] [PubMed]

50. Livesey, G.; Taylor, R.; Livesey, H.F.; Buyken, A.E.; Jenkins, D.J.A.; Augustin, L.S.A.; Sievenpiper, J.L.; Barclay, A.W.; Liu, S.; Wolever, T.M.S.; et al. Dietary Glycemic Index and Load and the Risk of Type 2 Diabetes: Assessment of Causal Relations. Nutrients 2019, 11, 1436. [CrossRef] [PubMed]

51. Wan, C.S.; Nankervis, A.; Teede, H.; Aroni, R. Dietary intervention strategies for ethnic Chinese women with gestational diabetes mellitus: A systematic review and meta-analysis. Nutr. Diet. J. Dietit. Assoc. Aust. 2019, 76, 211-232. [CrossRef]

52. Gilbertson, H.R.; Brand-Miller, J.C.; Thorburn, A.W.; Evans, S.; Chondros, P.; Werther, G.A. The effect of flexible low glycemic index dietary advice versus measured carbohydrate exchange diets on glycemic control in children with type 1 diabetes. Diabetes Care 2001, 24, 1137-1143. [CrossRef]

53. Esfahani, A.; Wong, J.M.; Mirrahimi, A.; Villa, C.R.; Kendall, C.W. The application of the glycemic index and glycemic load in weight loss: A review of the clinical evidence. IUBMB Life 2011, 63, 7-13. [CrossRef]

54. Zafar, M.I.; Mills, K.E.; Zheng, J.; Regmi, A.; Hu, S.Q.; Gou, L.; Chen, L.L. Low-glycemic index diets as an intervention for diabetes: A systematic review and meta-analysis. Am. J. Clin. Nutr. 2019, 110, 891-902. [CrossRef] [PubMed]

55. Miller, C.K.; Headings, A.; Peyrot, M.; Nagaraja, H. A behavioural intervention incorporating specific glycaemic index goals improves dietary quality, weight control and glycaemic control in adults with type 2 diabetes. Public Health Nutr. 2011, 14, 1303-1311. [CrossRef] [PubMed]

56. Nutrition and Metabolic Management Branch of China Association for the Promotion of International Exchanges in Healthcare; Clinical Nutrition Branch of Chinese Nutrition Society; Diabetes Branch of Chinese Medical Association; Parenteral and Enteral Nutrition Branch of Chinese Medical Association; Nutrition Physician Professional Committee of Chinese Medical Doctor Association. Guidelines for Medical Nutritional Treatment of Overweight/Obesity in China (2021). Chin. J. Front. Med. 2021, 13, 1-55. [CrossRef]

57. Thomas, D.E.; Elliott, E.J. The use of low-glycaemic index diets in diabetes control. Br. J. Nutr. 2010, 104, 797-802. [CrossRef] [PubMed]

58. Ebbeling, C.B.; Swain, J.F.; Feldman, H.A.; Wong, W.W.; Hachey, D.L.; Garcia-Lago, E.; Ludwig, D.S. Effects of dietary composition on energy expenditure during weight-loss maintenance. JAMA 2012, 307, 2627-2634. [CrossRef]

59. Hare-Bruun, H.; Nielsen, B.M.; Grau, K.; Oxlund, A.L.; Heitmann, B.L. Should glycemic index and glycemic load be considered in dietary recommendations? Nutr. Rev. 2008, 66, 569-590. [CrossRef] 